\title{
Poulbot - O Chatbot Extensionista Rural na Área de Incubação Artificial de Frangos de Corte
}

\author{
Aloísio Alkmim de Oliveira Filho, Vanessa Michalsky Barbosa, Gustavo Bittencourt \\ Machado, Taís Pinheiro Borges Silva, Tayana Nery Franca, Nayana Borges das Mercês, \\ Larissa Kiana Santos Azevedo Martins, Izabela Lorena Azevedo \\ ${ }^{1}$ Escola de Medicina Veterinária e Zootecnia - Universidade Federal da Bahia (UFBA) \\ Salvador, $\mathrm{Ba}-$ Brasil

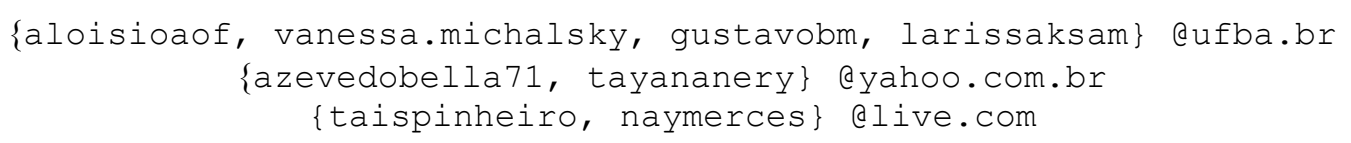

\begin{abstract}
Brazilian poultry is one of the main agribusiness sectors in the country, producing more than 13 million tonnes/year. It is a sector that has developed in the south and southeast regions with expressiveness, while other regions, such as North and Northeast, face a shortage of rural extension activity to serve small producers, although they have development potential. Thus, this work presents a proposal of a chatbot capable of offering support to the small producer in the artificial incubation area to produce broiler chicken chicks. Practical tests carried out showed that Poulbot successfully fulfills its role as an extension worker.
\end{abstract}

Resumo. A avicultura brasileira é um dos principais setores do agronegócio no país, que produz mais de 13 milhões de toneladas de carne de frango ao ano. É um setor que se desenvolveu na região Sul e Sudeste com mais expressividade, enquanto outras regiões, como o Norte e Nordeste, apesar de terem potencial de desenvolvimento, enfrentam carência nas atividades de extensão rural para auxiliar os pequenos produtores. Desta forma, este trabalho é uma proposta de chatbot capaz de oferecer suporte ao pequeno produtor na atividade de incubação artificial de ovos, com o objetivo de produzir pintinhos de frango de corte. Os testes práticos realizados demonstraram que o Poulbot cumpre com exito seu papel como extensionista.

\section{Introdução}

A avicultura brasileira é um dos principais setores do agronegócio no país, crescendo expressivamente, gerando emprego e produzindo proteína de qualidade a baixo custo para a população. Para os brasileiros consumirem um frango de qualidade, o processo adequado de incubação artificial é determinante, ou seja, é durante a incubação que ocorre o desenvolvimento embrionário, e assim, falhas neste período podem ocasionar eclosão de pintinhos de baixa qualidade, que terão desempenho prejudicado quando criados.

A produção animal necessita de profissionais especializados para assistir o produtor em questões como nutrição, bem-estar animal, sanidade, entre outros. Porém, sabe-se que no Brasil a assistência técnica rural é escassa e há uma discrepância de acesso entre as diversas regiões do país. Por outro lado, no período entre 2006 e 2017 houve um aumento de $1900 \%$ de pontos de internet em propriedades rurais, possibilitando a adoção 
de novas tecnologias que possam impulsionar a produção e assistir tecnicamente as propriedades que têm dificuldade de atendimento presencial (IBGE, 2017).

Esse avanço tecnológico vem favorecendo a criação de sistemas inteligentes e autônomos, como o chatbot, que permite a comunicação simplificada entre o humano e a máquina. Essa comunicação ocorre por meio da linguagem natural, ou movimentos utilizando sensores (Mostaço et al., 2018), que podem ser caracterizados de duas formas: com base em regras, por meio de palavras chaves, produzindo uma conversa bem direcionada; ou baseado em inteligência artificial, para aumentar assim a capacidade de diálogo.

Diante destes fatores e considerando a popularização do uso de chatbots pela sociedade, nosso objetivo com o presente trabalho foi criar de forma inédita o "Poulbot": um chatbot com a finalidade de ser um extensionista de qualidade na área de incubação artificial para pequenos produtores de frango de corte.

Este artigo está organizado da seguinte forma: na Seção 2 a avicultura brasileira é apresentada e na Seção 3 comenta-se sobre a extensão rural no Brasil e sua discrepância. A Seção 4 define o que é chatbot. Na Seção 5 é demonstrado o desenvolvimento do "Poulbot" e na Seção 6 o teste de usabilidade. Os resultados e discussão encontram-se na Seção 7 e na Seção 8 a conclusão e a intenção de pesquisa futura.

\section{Avicultura Brasileira}

A avicultura é o ramo da zootecnia especializado na criação de aves, para a produção de carne e ovos como fonte proteica, principalmente da espécie Gallus gallus domesticus. A avicultura brasileira é hoje o setor de maior destaque na produção de alimentos, ocupando o ranking de maior exportador de carne de frango do mundo, à frente dos Estados Unidos e União Europeia (USDA, 2019). É um exemplo de competitividade a nível global, como uma produção bem-organizada, com alto poder tecnológico aliada a uma ótima gestão. No Brasil, a região de maior de maior destaque é a Sul, representando $64,41 \%$ do total da produção de frangos de corte em 2019, e a menor produção vem da Região Norte, com apenas $1,16 \%$ do total que é produzido no país. Os dois maiores estados exportadores são o Paraná $(39,13 \%)$, seguindo pelo estado de Santa Catarina com 30,53\% do total exportado pelo Brasil (ABPA, 2020).

Por muito tempo a incubação não era considerada uma área estratégica na avicultura. Entretanto, com as evidências de novas pesquisas, a incubação passou a ser uma área essencial na produção de aves (Calil, 2007). A incubação de ovos férteis é a base de toda a produção avícola, visto que é o período primordial de desenvolvimento da ave. $\mathrm{O}$ processo de incubação artificial consiste no recebimento de ovos férteis pelas granjas e a produção de pintinhos, por meio do fornecimento de condições ideais de temperatura, umidade, ventilação e viragem para que o embrião se desenvolva adequadamente. Esse desenvolvimento é refletido no campo, pois se houver alguma intercorrência na incubação, os pintinhos terão baixa qualidade e o desempenho da criação será prejudicado. Assim, tanto o produtor quanto o consumidor terão um produto de baixa qualidade, e em consequência, menor competitividade no sistema de produção.

\section{Extensão Rural}

O termo extensão rural tem origem no século XIX nas extensões que as universidades inglesas praticavam. Nos Estados Unidos tivemos a criação do serviço cooperativo de 
extensão rural no século XX, que reuniam universidades, consolidando assim a instituição da extensão rural (Jones e Garforth, 1997). O termo extensão rural literalmente, significa, levar ou transmitir conhecimentos de sua fonte geradora para o público rural, e em um sentido mais amplo significa o processo educativo de comunicação (Peixoto, 2008). Este trabalho papel social muito forte, que é o de diminuir o êxodo rural, fazendo com que os filhos desses produtores tenham a perspectiva de futuro no meio rural, diminuindo assim a busca por uma fonte de renda em um centro urbano.

Por ter uma extensão territorial vasta, no Brasil muitas vezes encontramos grandes paradoxos, como é o caso de regiões onde temos uma alta demanda por extensão rural, enquanto outras regiões nem sabem do que se trata. Assim um desafio para o país é oferecer extensão rural a todos os produtores de diferentes regiões. As regiões do país com um maior índice de IDH são justamente aquelas que recebem maior apoio a extensão rural, como é o caso da região Sul e Sudeste. As que menos recebem esse apoio estão nas regiões Norte e Nordeste (IBGE, 2017). Segundo dados do IBGE, no ano de 2017 a região Sul do país recebeu cerca de $48,6 \%$ em assistência técnica, enquanto o Nordeste brasileiro recebeu apenas $7,4 \%$.

\section{Chatbot}

Conhecido também pelo termo chatterbot ou agente conversacional, é um sistema que tem a capacidade de se comunicar com um usuário humano em linguagem natural (Moraes et al., 2015). As aplicações de um chatbot variam muito de acordo com a necessidade do usuário, podendo ser utilizado em canais de e-commerce, serviço de atendimento ao cliente, na educação, entre outros. O chatbot é um programa com uma interface gráfica que necessita de entradas e saídas de dados, pois assim ele vai realizar a interação com o usuário.

\section{Desenvolvimento do "Poulbot"}

Este trabalho foi realizado pelo NUPIA - Núcleo Brasileiro de Pesquisa em Incubação Artificial de Ovos. O chatbot foi desenvolvido pela plataforma Dialogflow ${ }^{\circledR}$, pertencente a marca Google ${ }^{\circledR}$, que possui código fechado, porém com integração com os principais

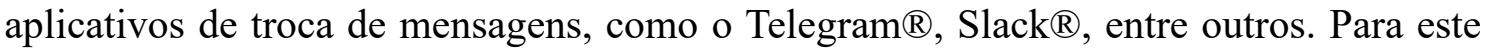
projeto, o aplicativo de integração escolhido foi o Telegram ${ }^{\circledR}$, por ser amplamente difundido pelo público-alvo em relação aos outros aplicativos disponíveis. O sistema consiste em responder questões pré-definidas referentes ao processo de incubação artificial. O software permite adicionar novas respostas a base de dados, sendo o idioma utilizado nesta comunicação o português.

As mensagens enviadas para o chatbot são redirecionadas para a plataforma, através de Processamento de Linguagem Natural. As sequências de caracteres são convertidas em objetos e são devidamente tratadas pelo agente, considerando o padrão definido de aprendizado de máquina e assim retornando para o usuário. Esse treinamento é feito automaticamente pela plataforma. As interações permitem que o agente entenda a motivação por meio de uma entrada de usuário específica. Assim, as entidades extraem dados úteis de entradas de linguagem natural e utilizam estas informações para enviar a interação que mais se adeque a solicitação do usuário. Desta forma o contexto controla o fluxo de conversas, permitindo ao agente transmitir essas informações aos parâmetros; que são dados estruturados que podem ser utilizados para gerar respostas. 
O robô envia mensagens de texto simples e de fácil compreensão, e para facilitar o entendimento do usuário, o robô envia juntamente com o texto, uma imagem e algumas vezes recomenda vídeos do Youtube ${ }^{\circledR}$. O acesso ao Poulbot está disponível no link t.me/Poulbot bot.

\section{Teste de Usabilidade do "Poulbot"}

Para a realização do teste de usabilidade, foram selecionados na Região Nordeste, 15 pequenos produtores de frango de corte, que também realizam a incubação de ovos. Foi enviado um link para que eles pudessem fazer a utilização do "Poulbot", durante o período de uma semana. Ao final deste período de teste foi enviado aos produtores um questionário contendo cinco perguntas, sendo elas: 1) se a interação foi próxima a um humano; 2) sobre a facilidade ao utilizar o sistema; 3) se a interação esclareceu a dúvida do usuário; 4) se as respostas foram coerentes; 5) se o produtor indicaria o "Poulbot" para amigos.

\section{Resultados e Discussão}

Considerando as respostas obtidas ao final do teste de usabilidade (Tabela 1), em relação a pergunta se os usuários se sentiram interagindo com outro humano, $80 \%$ afirmaram que sim, e isso se deve provavelmente, as respostas amigáveis que foram inseridas no sistema. Este questionamento foi inserido no teste de usabilidade baseado no Teste de Turing (1950), que verifica a capacidade de uma máquina exibir comportamento inteligente equivalente a um ser humano ou indistinguível deste. Esta capacidade é um conceito fundamental da filosofia da inteligência artificial.

Quanto a questão se os usuários sentiram alguma dificuldade em utilizar a ferramenta, 73,3\% afirmaram que não tiveram dificuldade, comprovando desta forma, que é um sistema simples de manusear.

$66,7 \%$ dos produtores afirmaram que a interação entre o "Poulbot" e o usuário esclareceu a dúvida sobre algum aspecto da incubação artificial. Quanto a questão de se as respostas oferecidas pelo sistema foram coerentes com a pergunta realizada pelos usuários, também $66,7 \%$ afirmaram que sim. Este resultado demonstra que o chatbot pode ser utilizado como um suporte na extensão rural, pois contribui com informações necessárias e de fácil compreensão. Apesar da grande maioria declarar o esclarecimento de dúvidas e a coerência entre perguntas e respostas, por se tratar de um sistema novo e experimental, a tendência é que este percentual positivo ainda se eleve com o aumento do uso do "Poulbot", visto que, há um aperfeiçoamento da interação do sistema à medida que o mesmo vai sendo utilizado.

Em relação a indicar o "Poulbot" para amigos, 53,3\% dos usuários afirmaram que o fariam, revelando que no meio rural cujo teste foi aplicado, existem pequenos produtores receptivos a se adequarem e difundirem as novas tecnologias disponíveis no mercado avícola. Entretanto, 48,7\% afirmaram o contrário, e justificaram que ainda há uma resistência em também "dialogar com uma máquina" e não somente com um profissional técnico de forma presencial. Assim, além da disponibilização do "Poulbot" como uma ferramenta auxiliar para a produção de pintinhos, torna-se necessário incentivar o uso do mesmo, por meio de um acompanhamento inicial daqueles produtores que ainda não se familiarizaram com esta nova possibilidade de extensão rural. 


\section{Conclusão e Trabalhos Futuros}

De acordo com os dados apresentados neste trabalho, concluímos que a utilização de chatbot como forma de extensionismo rural é de grande valia, visto que o objetivo de apoiar tecnicamente e transmitir conhecimento para o produtor rural de forma simples, acessível e compreensível, foi cumprido.

Como trabalho futuro vislumbra-se a expansão do "Poulbot" para todo o processo de produção avícola, incluindo a fase de criação do frango e de galinhas poedeiras. A partir da consolidação do "Poulbot" também pretendemos dar suporte a criação desta ferramenta para atendimento aos demais segmentos da produção animal.

\section{Referências}

ABPA. Relatório anual 2020. São Paulo: 12/05/2020, 159p.

CALIL, T.A.C. Princípios básicos de incubação. In: Simpósio sobre incubação da Conferência APINCO, Santos, São Paulo, Brasil, 2007.

DIALOGFLOW. Dialogflow Enterprise Edition BETA. 2017. https://cloud.google.com/dialogflow-enterprise/. Accesso em: 02/02/2021

IBGE: Censo Agropecuário 2017. https://sidra.ibge.gov.br. 2017. Disponível em $<$ https://sidra.ibge.gov.br/pesquisa/censo-agropecuario/censo-agropecuario-2017>. Acesso em: 02/02/2021.

JONES, Gwyn E. and GARFORTH, Chris. "The history, development, and future of agricultural extension", in Swanson, Burton E., Bentz, Robert P. and Sofranko, Andrew J. (eds.). Improving agricultural extension - A reference manual. Rome: Food and Agriculture Organization of the United Nations, 1997, $316 \mathrm{p}$.

MORAES, Sílvia M. W.; DE SOUZA, Luciano Severo. Uma Abordagem Semiautomática para Expansão e Enriquecimento Linguístico de Bases AIML para Chatbots. In: Congresso Internacional de Informática Educativa, 20., 2015, Santiago. Anais. Santiago: Universidad de Chile, p. 600-605, 2015.

MOSTAÇO, G. M.; SOUZA, I. C. R.; CAMPOS, L. B.; CUNGNASCA, C. E. AgronomoBot: a smart answering Chatbot applied to agricultural sensor networks in 14th International Conference on Precision Agriculture June 24 - June 27, 2018 Montreal, Quebec, Canada

PEIXOTO, M. EXTENSÃO RURAL NO BRASIL - UMAABORDAGEM HISTÓRICA DA LEGISLAÇÃO, Textos para discussão, Brasília, No 48, outubro 2008

SALES, M.N.G. Criação de galinhas em sistemas agroecológicos. Vitória: Incaper, 2005. $284 \mathrm{p}$.

TURING, A. Computing machinery and intelligence. Mind, v. 59, p. 433-460, 1950.

USDA (UNITED STATES DEPARTMENT OF AGRICULTURE), Foreign Agricultural Service. Disponível em: https://usdabrazil.org.br/wpcontent/uploads/2020/06/poultry-and-products-annual-report-2019.pdf. Acesso em: 02/20/2021. 